\title{
HR analytics a roadmap for decision making: case study
}

\author{
Brahim Jabir, Noureddine Falih, Khalid Rahmani \\ LIMATI Laboratory Polydisciplinary Faculty, University of Sultan Moulay Slimane, Morocco
}

\begin{tabular}{l} 
Article Info \\
\hline Article history: \\
Received Oct 19, 2018 \\
Revised Feb 14, 2019 \\
Accepted Mar 05, 2019 \\
\hline
\end{tabular}

\section{Keywords:}

Analytic framework

Business analytics

Decision making

Hr analytics

Predictions

\begin{abstract}
In the socio-economic world, the human resources are in the most top phase of the enterprise evolution. This evolution began when the arithmetic, statistics are applicable over a vast of opportunities and used to identify problems and support decision. However, analytics has been emerged to provide predictions and understand the people performance based on available data. In light of this vast amount of information, human resources services need to deploy a predictive management model and operating system of analytics that can be an efficient and an instead solution that can respond to the gaps of the traditional existing ones and facilitate the decision making. In this paper, we present a literature review of this HR analytics concept and a case study concerning the impact of interventions using an analytics solution.
\end{abstract}

Copyright () 2019 Institute of Advanced Engineering and Science. All rights reserved.

Corresponding Author:

Brahim Jabir,

LIMATI Laboratory of Polydisciplinary Faculty,

University of Sultan Moulay Slimane Beni Mellal,

Mghila, BP 592 Beni Mellal, Morocco.

Email: ibra.jabir@gmail.com

\section{INTRODUCTION}

Over the past years, Human Resources experts spend a lot of time and effort producing the report, managing the business planning and trying to better understand customers but now the emergence of analytics methods facilitated the task and solve complex problems in the case of decision making [1], and made organizational management able to understand what they don't yet know [2].

HR analytics is a systematic application of predictive modeling using sophisticated statistics and quantitative analyses tools that enterprise uses to predict things and apply them to extract value from information [3], for a better understanding of customer and employee behaviors. For example, what might drive the best performance, or what might cause employee change the company? The question arises here is: how can HR analytics help with improving the business and performance?

\section{HR ANALYTIC MODEL}

HR has adopted the usage of technology and demonstrate huge impact on the HR practices and processes [4] so Human Resource analytics (HR analytics) emerged as a reliable business management model, uses analytics capabilities to make a decision [5]. It is about analyzing and understanding how and why things happen, produces alerts about what is the next best actions, and make interpretation about what is the best and the worst that can happen, Moreover HR decisions are based on reporting and predictions and no longer on feelings [6], for example, it answers business questions to predict and get information about:

a) The employee who probably has good performance.

b) The employee who is likely to leave.

c) The impact of some intervention.

d) Candidates are likely to succeed in the company. 
e) Which could lead to high performance?

f) What might cause customers to leave the purchase?

g) The risk of losing money on the new business investment.

h) The expectation regarding the payment of direct and indirect costs.

i) The best way to minimize costs and fees.

j) The impact of each intervention.

It is clear that the traditional methods of human resources management cannot answer most of these questions, it needs to collect large amounts of HR data and analyze it using analytics tools in order to extract value and knowledge. As soon as the company starts to analyze the problems of employees using the available data, it is engaged in HR analytics as shown in Figure 1 [7].

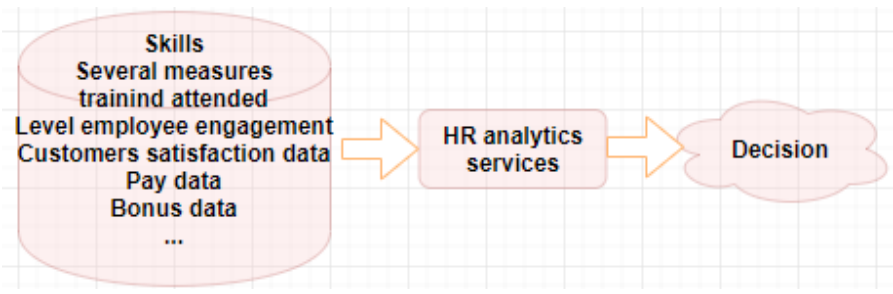

Figure 1. HR analytics perspectives

\section{TYPES OF ANALYTICS}

To better understand this concept of analytics, it is necessary to understand it, through its three types, which summarize its role and goals.

\subsection{Descriptive Analytics}

This type of analytics also known as business reporting provides an interpretation and extrapolation of historical data to understand the major change in the company and provide insight into the past event [8]. Its main result is making the raw data understandable for the various components of the company (managers, investors, and other stakeholders...), this allows the company to answer the questions of "what happened" or "what happening" [9] like:

a) How many products have been delivered last months?

b) What is the average sales volume for the last month?

c) What is the rate of the products returned for last month?

d) What are the best-selling products?

e) How many customers registered last month?

f) How much paid for the direct and indirect costs last year?

This analytics type uses many techniques and tools such as data mining, and data aggregation to provide information and creates a summary of historical data and prepare it for further processing in order to provide insights and predictions that can help to understand why and how some event happened and explain why some results occur, all while trying to improve employee engagement and productivity.

\subsection{Predictive Analytics}

Predictive analytics is a branch of analytics come as a kind of analytic modeling, involves several statistical tools that can analyze current and historical events in order to provide insights and make predictions about unknown events and/or about future [10].

HR experts use this type to deploy future business planning to predict the problems before they occur, discover new services and more opportunities to reduce time, increase productivity and minimize risks. Its major outcome is to answer the question of " what will happen? " or " why will it happen?" Examples:

a) Who is the most likely employee to leave our organization?

b) What is the risk of losing on new project investment?

c) What will be the revenue if sales service decreases by $\mathrm{X}$ percent?

d) What will the revenue be if a boycott is applied for an $\mathrm{X}$ time?

e) What will happen if supplier prices increase by an $X$ percent?

f) What do we expect to pay for $X$ services over the next year? 
By answering these questions, the company explores the results to find new patterns and relationships to improve their performance through its various business areas, operations, finance, and marketing.

\subsection{Prescriptive Analytics}

Prescriptive analytics is the final stage of analytics. It describes the actions to be taken to avoid future risk or to take full advantage of a promising trend, using historical data, and external information due to the nature of statistical algorithms to identify opportunities and identify the reasons behind failure or success. Prescriptive analytics uses sophisticated tools and technologies, like machine learning, business rules, and algorithm. It answers the question of " what I should do? " and/or " why should I do it?" [11], Examples:

a. What is the alternative plan to maintain maximum profit if $\mathrm{X}$ employee leave?

b. How many products do we need to sell to maximize revenue?

c. What is the best way to minimize costs and fees?

The answers were given by this model help the company set new criteria for success and failure in order to transform the business with reliable predictions to improve efficiency and reduce costs. Figure 2 shows the analysis levels of the business analytics which clarifies that descriptive analytics provide insights into the past, predictive Analytics help to understand the future and prescriptive analytics to advise on possible outcomes.

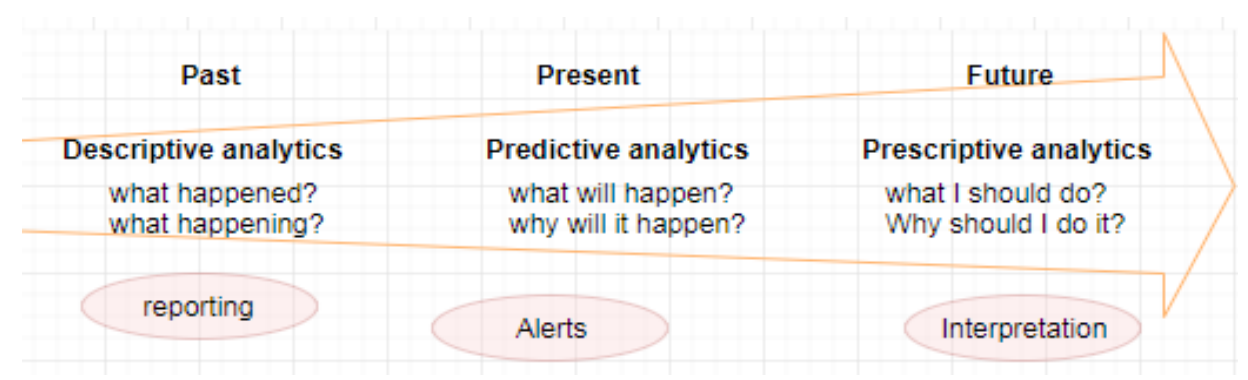

Figure 2. Business analytics view

\section{HR INFORMATION SYSTEMS AND DATA}

As we show previously, HR analytics can bring many benefits to the company using available data come from several sources to extract meanings through a systematic analysis [12]. In this section, we present examples of information sources examples, the analytics systems existed and different stages of preparing and analyzing data.

\subsection{Information Sources}

The available information varies greatly in its volume, its format, and the speed depending on the type of the company. It is necessary that information combine data typically managed by the HR department, customer satisfaction and operational data. It is noted that decision-making needs the right kind of information, the complete information and the ability to synthesize and make sense of the information in an organizational context [13]. This data expanded, linked and analyzed with several tools in order to find what really happening in the organization and discover what will happen and what should the organization do. Some examples of the types of data are described in the Table 1.

\subsection{Analytics Solutions}

In this section, we describe the current analytics solutions that can be a major key to create and deploy an efficient predictive management model. This analytic management model will produce predictions and insights and help HR managers make better decisions for the company. Of course, most of them are expensive but there is a lot of similarity between the packages, and the analysis generally produces the same results. So, all you need is analytics methods and skills, and it is possible to apply them in most other systems. We consolidate in Table 2 the most popular analytics system with some details: 
Table 1. Various Data Sources and Details

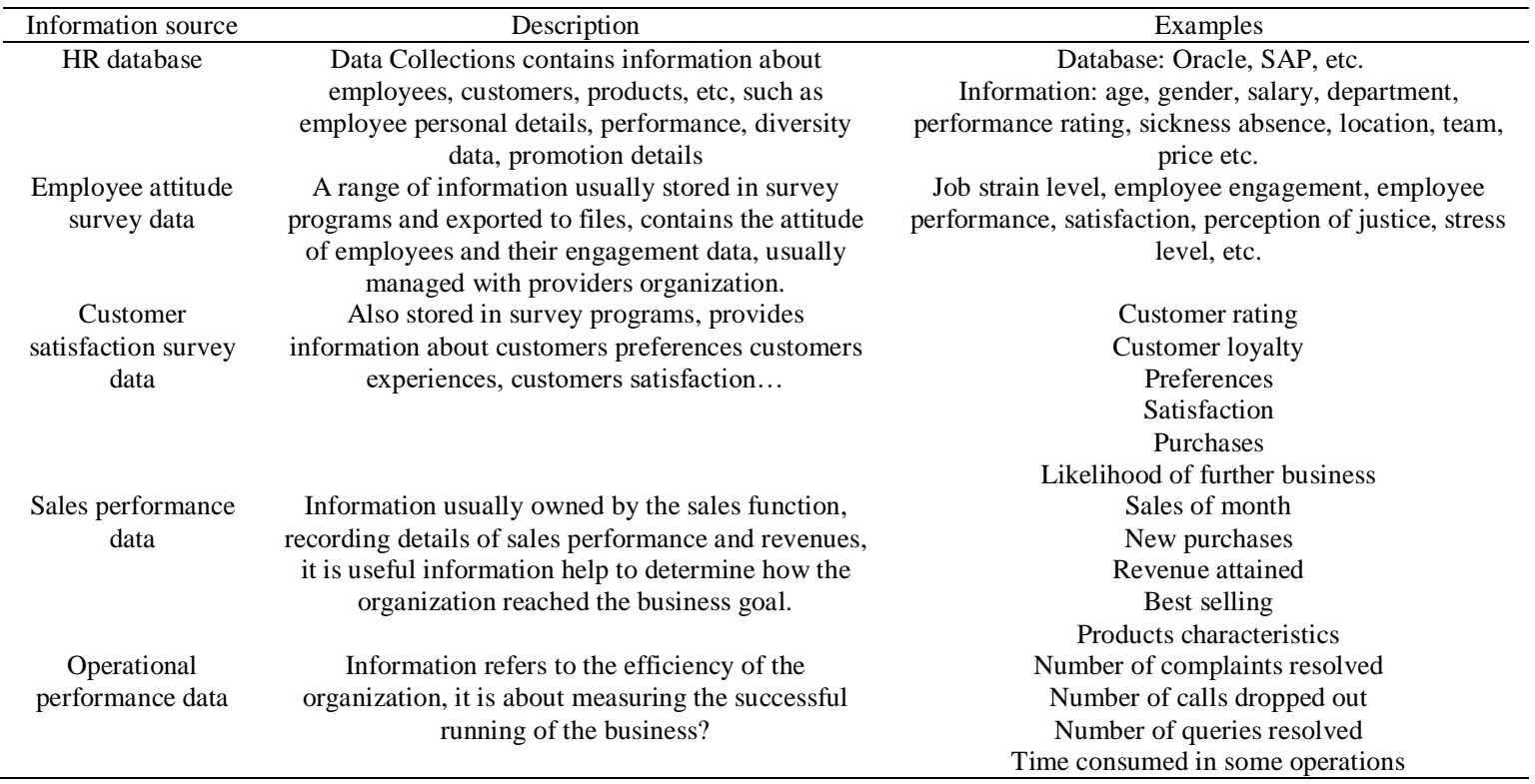

Table 2. Popular Analytics Software with Details

\begin{tabular}{|c|c|}
\hline Analysis software system & Details \\
\hline SPSS & $\begin{array}{l}\text { SPSS Statistical Package for the Social sciences, is a software program which can be used for } \\
\text { doing statistical analysis of the collected data [14], based on hypothesis testing, ad-hoc analysis, } \\
\text { predictive analytics modeling, geospatial analysis, etc. It is an efficient solution comes to solve } \\
\text { business and research problems. SPSS Offers a graphical user interface facilitates running the } \\
\text { procedures, and it is able to export and transfer the result to other formats for reporting. }\end{array}$ \\
\hline Minitab & $\begin{array}{l}\text { Minitab is a special analytics software developed at the Pennsylvania State University in } 1972 \text {, } \\
\text { easy to use, enables users to do most analysis procedures without having to understand the } \\
\text { syntax, it offers a reliable calculations and produce a valuable drawings and graphs, allows the } \\
\text { user to focus more on the interpretation of results, uses to helps businesses increase efficiency } \\
\text { and improve business quality through smart data analysis [15]. }\end{array}$ \\
\hline Stata & $\begin{array}{l}\text { Stata (statistics and data) is an analytics software package developed by StataCorp in 1985, it can } \\
\text { analyze any size of data once it is in the system, what makes from it an accurate solution, it } \\
\text { includes a graphical user interface also a command-line interface, which facilitates monitoring } \\
\text { analyses. The system capabilities include data management, statistical analysis, graphics, } \\
\text { simulations, regression, and custom programming [16]. }\end{array}$ \\
\hline SAS & $\begin{array}{l}\text { SAS (Statistical Analysis System) is an advanced analytics software, developed by SAS Institute } \\
\text { for advanced analytics, its development started in } 1976 \text {, it is an efficient solution mine, alter, } \\
\text { manage and retrieve data from several sources, it includes a graphical user interface facilitating } \\
\text { the manipulation [17]. }\end{array}$ \\
\hline $\mathrm{R}$ & $\begin{array}{l}\mathrm{R} \text { is from the most famous statistical system solutions, it is developed as a language inspired } \\
\text { from } \mathrm{S} \text { language by Ross Ihaka and Robert Gentleman, and also a platform for statistical } \\
\text { computing. This technique } \mathrm{R} \text { offers a broad diversity of statistical methods as linear and } \\
\text { nonlinear modeling, classical statistical tests, time-series analysis, clustering algorithms, also } \\
\text { provide a graphical presentation. }\end{array}$ \\
\hline JASP & $\begin{array}{l}\text { JASP is a free and open source technique of data includes several algorithms for data mining } \\
\text { operations, easy to use, offers standard analysis procedures, and the possibility to export the } \\
\text { results to other formats. It allows enterprises to discover structure in data store systems, provides } \\
\text { insights and predictions, and almost improves their performance through interaction } \\
\text { with data [18]. }\end{array}$ \\
\hline
\end{tabular}

\subsection{Solution's Limits}

In this part, we present a comparison between the several analytics solutions detailed above, annotated by their weakness and their robust features, the list below illustrates the critical capabilities considered in this comparison process and Highlights the Advantages and Disadvantages of the Analytics Solutions as shown in Table 3:
a. Licensing
b. Data Source handling
c. Graphics facilitation
d. Meta-data Management 
e. Level of simplicity

f. Scalability

g. Dependency

h. Real-time operations

i. Advanced Analytics

j. Security

k. Fault tolerance

Table 3. Highlights the Advantages and Disadvantages of the Analytics Solutions

\begin{tabular}{|c|c|c|}
\hline Software & Weakness & Strength \\
\hline \multirow{4}{*}{ SPSS } & $\begin{array}{c}\text { Not efficient with a large volume of } \\
\text { information }\end{array}$ & $\begin{array}{c}\text { Possibility for coding syntaxes } \\
\text { Cover almost of statistical procedures }\end{array}$ \\
\hline & Requires skills in statistics to make the most of it. & Able to transfer the result to other formats \\
\hline & Expensive & $\begin{array}{l}\text { Provides chart and graphs with precision } \\
\text { Don't need other similar software }\end{array}$ \\
\hline & & $\begin{array}{l}\text { Adapts to the needs of the statistical studies. } \\
\text { Safe and secure }\end{array}$ \\
\hline \multirow{7}{*}{ Minitab } & Problems with native statistical & Exports to MS Word, and PowerPoint and others \\
\hline & Poor graphics facilities & Provides Real-time Insights \\
\hline & Cannot easily read data from other packages & Don't need understanding code syntax \\
\hline & Spreadsheet not easily manipulated & Transfer results to other formats \\
\hline & Don't offer sufficient coverage at econometric & Easy to use \\
\hline & methods & Good help facilities \\
\hline & Not scalable & $\begin{array}{c}\text { Provides quick draw graphics offer a quick look in } \\
\text { analysis }\end{array}$ \\
\hline \multirow{7}{*}{ Stata } & Difficult to manage multiple datasets at once & Cost fairly reasonable \\
\hline & Weak visualizations capabilities & Best for complex statistical analyses \\
\hline & Difficult to interpret the results without & Offers an intuitive window \\
\hline & experiences & Provides professional output tables. \\
\hline & Need time for processing & Produce basic graphs \\
\hline & Difficult for coding the requested commands. & streaming processing \\
\hline & Lack of documentation & Clarity of operations and feedback \\
\hline \multirow{7}{*}{ SAS } & Difficult to export the result to other systems & \\
\hline & Not flexible & \\
\hline & Very costly & Excellent documentation \\
\hline & Requires skills to interpret results & Manipulate, and analyze large datasets \\
\hline & Graphs and other visualizations aren't good & Process data seamlessly \\
\hline & Has a lot of bugs & Applicable to every aspect of analytics \\
\hline & & $\begin{array}{l}\text { Can do sophisticated statistical analyses } \\
\text { Reliable and respected results }\end{array}$ \\
\hline \multirow{4}{*}{$\mathrm{R}$} & Need time for accessing new algorithms & Open source \\
\hline & Lack of comprehensiveness of the econometrics & Better visualizations \\
\hline & packages & Easier for writing functions and custom packages \\
\hline & Need skills to manage & Flexible \\
\hline \multirow{4}{*}{ JASP } & Not possible to do any changes & Free and open-source, \\
\hline & $\begin{array}{c}\text { Often need additional software for data cleaning } \\
\text { and munging. }\end{array}$ & $\begin{array}{c}\text { Offers a targeted and popular series of tests, } \\
\text { Offers updates }\end{array}$ \\
\hline & Need some skills to use & Easy of use and to install \\
\hline & saving or scripting analysis Pipelines not simple & $\begin{array}{l}\text { Simple and attractive graphical user interface } \\
\text { Real-time processing }\end{array}$ \\
\hline
\end{tabular}

As it is clear that almost all the available analytics solutions suffer from problems and require strong skills to use and to manage it, in the next section, we will talk over the using of JASP system, and a case study about tracking the impact of interventions and its benefits on investment.

\section{RESEARCH METHOD}

The proposed approach is based mainly on a smart framework that comes to offers a solution to the gaps encountered in the standard analysis. In the following section, we give a case study and then discuss the strong then the weaknesses of those traditional solutions then we present a proposed framework with a semantics constructs contributed to reducing the margin of error caused by traditional solutions.

\subsection{Reason for Choosing JASP}

We have decided to use JASP in the analysis of our case study because of its free license, open source supported from the Amsterdam's University, and it's the one we have the experience. Generally, the 
results are the same regardless of the software used. Moreover, most of the analytics systems have the same packages, so we only need to know one system and get experience about it and apply it to other systems.

\subsection{Using JASP}

In this section we talk about JASP as a powerful statistical system, we elaborate on a case study in which we recommend a particular form of analysis and discuss results. JASP offers primary analysis which contains the most popular statistical modems in the social science (regression, frequencies, ANOVA, T-test), the JASP data view as shown in Figure 3 has the same appearance to a Microsoft Excel, it offers the possibility to enter the values manually or import it from another source [19]:

\begin{tabular}{|c|c|c|c|c|c|}
\hline File & Common & \multicolumn{4}{|l|}{+} \\
\hline$\|_{\text {Descriptives }}$ & \multicolumn{2}{|c|}{$\frac{\mid \Phi \Phi}{\text { T-Tests }}$} & $\frac{+4+4}{\text { Regression }}$ & \multirow{2}{*}{$\begin{array}{c}\underbrace{}_{\text {Frequencies }} \\
\text { StressT2 }\end{array}$} & $\begin{array}{l}\text { Aitor } \\
\text { Factor }\end{array}$ \\
\hline $\boldsymbol{T}$ & EmployeeID & Gender & StressT1 & & \\
\hline 1 & 5422 & 1 & 3 & 4 & \\
\hline 2 & 5423 & 1 & 2 & 4 & \\
\hline 3 & 5424 & 2 & 2 & 3 & \\
\hline 4 & 5425 & 1 & 3 & 3 & \\
\hline 5 & 5426 & 2 & 4 & 4 & \\
\hline 6 & 5427 & 2 & 1 & 3 & \\
\hline 7 & 5428 & 1 & 1 & 2 & \\
\hline 8 & 5429 & 1 & 2 & 4 & \\
\hline 9 & 5430 & 2 & 1 & 2 & \\
\hline 10 & 5431 & 1 & 3 & 3 & \\
\hline 11 & 5432 & 2 & 2 & 3 & \\
\hline 12 & 5433 & 1 & 4 & 4 & \\
\hline 13 & 5434 & 1 & 2 & 5 & \\
\hline 14 & 5435 & 2 & 3 & 4 & \\
\hline 15 & 5436 & 2 & 1 & 3 & \\
\hline 16 & 5437 & 1 & 2 & 3 & \\
\hline 17 & 5438 & 2 & 3 & 4 & \\
\hline 18 & 5439 & 1 & 3 & 5 & \\
\hline
\end{tabular}

Figure 3. The JASP data view

The figure below illustrates key pieces of information: each row is a case, each column is a variable representing characteristics or attribute, then each cell is a value showing the variable for the case or attribute, etc.

Data may be passed on the following stages:

a. Preparing data: typing data, loading data from other sources, copying data from files...

b. Setting variables: JASP distinguishes between four variable types; Nominal Text, Nominal, Ordinal, and Continuous, JASP automatically assigns theses variable types according to the specific rules, but it is possible to change it manually if it is necessary.

c. Run analyses. After selecting the suitable statistic models (regression, frequencies, ANOVA, T-test).

\subsection{Case Study: Measuring the Impact of the $\mathrm{Hr}$ Interventions Using JASP}

Measuring and evaluating the impact of an HR intervention is one of the most important tasks in a human resources management process, it has a direct influence on financial investment. To understand this concept, we can study for example: a regular training program that is costing a lot of money and whose evaluation of the effectiveness of these courses remains an unavoidable task.

The important question is: what intervention, what to measure? it is important that HR experts determine the best indicators, create the index and metric for the measure that will influence the intervention 
and track to assess the impact of intervention, sometimes it is easy to find indicators: for example: absence rate of illness, employee engagement levels, satisfaction at work, levels of stress or psychological tension and that's our object of study. Generally, HR analytics experts recommend that the enterprise create new ways to measure and track particular perceptions, attitudes, behaviors, or performance indicators in order to monitor the effectiveness of an HR intervention.

\subsubsection{Algorithm Used}

Paired sample t-test is one of the statistical procedures most known, used to explore the change overtime-related to the same object or entity (employee). This model determines two sets of data from the same individual or object, then find out if is there a difference between two sets of observations, in another way if there is a significant change in the metrics over time [20].

Stress is a known problem in work, working hours as well as the presence of motivations being directly related to the signs of anxiety, depression and reported sleep problems [21]. The organization has developed a survey identified work pressure; firstly, she set up a comfortable work program for employees with a flexible number of hours, with a set of financial and social motivations, it conducted a survey that measures the level of stress before the new program (T1 stress). and after 3 months of change (of the new program), it distributed a questionnaire to measure the same level of stress (stressT2). The set of found data that will be analyzed and explored is contained in a file. This file contains relatively simple information with four variables collected from 406 employees, these are:

a. ID_Employee: Number identification of the employee concerned by this program.

b. Gender: $1=$ male, $2=$ female.

c. T1_Stress: level of stress before the change. 1 to $5,1=$ very low level of stress; 5 very high level of stress.

d. T2_Stress: level of stress after the change. 1 to $5,1=$ very low level of stress; 5 very high level of stress.

Before applying the Sample t-test model, we check the statistics as the difference between the mean stress level after the intervention and before then the average stress level after and before the change intervention as shown in Figure 4:

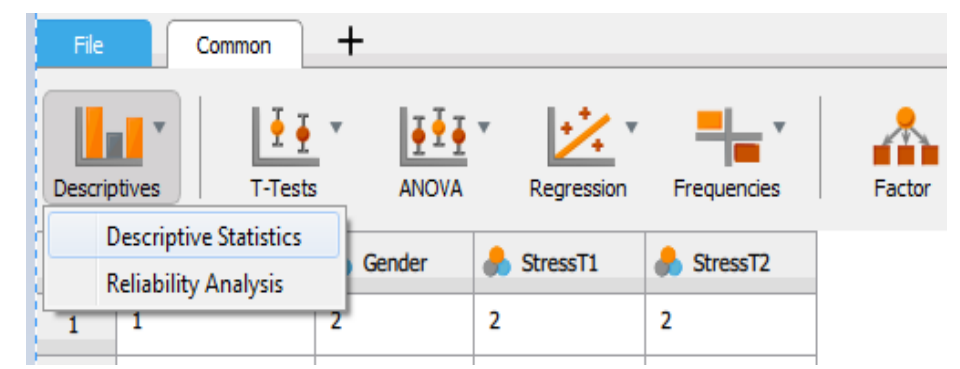

Figure 4. JASP descriptive information

The JASP results generated from this analysis shows the descriptive information as shown in Figure 5 about two attributes which the stress variable at T1: after the intervention, and at T2: before the intervention. The average of stress at T1 is: 3.595 , this value is higher than at the time 2 which is 2.216 (Note that 5 is the highest level and 1 is the lowest).

\begin{tabular}{lrr}
\multicolumn{3}{l}{ Descriptive Statistics } \\
\hline & StressT1 & StressT2 \\
\hline Valid & 402 & 402 \\
Missing & 5 & 5 \\
Mean & 3.595 & 2.216 \\
Std. Deviation & 1.106 & 0.9318 \\
Minimum & 1.000 & 1.000 \\
Maximum & 5.000 & 5.000 \\
\hline
\end{tabular}

Figure 5. Descriptive information about stress level at time 1 and stress level at time 2 
Figure 6 shows other information related to the two parameters stressT1 and stressT2, the most important is the frequencies and the percentage of each scale of stress level $(1,2,3,4,5)$ in time 1 and the time2, as it is clear, that level 3 is the dominant in period T1, as level 2 is the most dominant in period T2, means that the number of employees who have a high level of stress has decreased during period 2 ( 3 vs 2 ). The box shows also the number of missing variable that is 5 in this case.

\begin{tabular}{|c|c|c|c|c|}
\hline \multicolumn{5}{|c|}{$\begin{array}{l}\text { Frequencies } \\
\text { Frequencies for StressT1 }\end{array}$} \\
\hline StressT1 & Frequency & Percent & Valid Percent & Cumulative Percent \\
\hline 1 & 11 & 2.7 & 2.7 & 2.7 \\
\hline 2 & 56 & 13.8 & 13.9 & 16.7 \\
\hline 3 & 126 & 31.0 & 31.3 & 48.0 \\
\hline 4 & 101 & 24.8 & 25.1 & 73.1 \\
\hline 5 & 108 & 26.5 & 26.9 & 100.0 \\
\hline Missing & 5 & 1.2 & & \\
\hline Total & 407 & 100.0 & & \\
\hline \multicolumn{5}{|c|}{ Frequencies for Stress T2 } \\
\hline StressT2 & Frequency & Percent & Valid Percent & Cumulative Percent \\
\hline 1 & 95 & 23.3 & 23.6 & 23.6 \\
\hline 2 & 166 & 40.8 & 41.3 & 64.9 \\
\hline 3 & 104 & 25.6 & 25.9 & 90.8 \\
\hline 4 & 33 & 8.1 & 8.2 & 99.0 \\
\hline 5 & 4 & 1.0 & 1.0 & 100.0 \\
\hline Missing & 5 & 1.2 & & \\
\hline Total & 407 & 100.0 & & \\
\hline
\end{tabular}

Figure 6. Frequencies and the percentage of each stress level scale $(1,2,3,4,5)$ in the Time1 and Time2

If we focus only on the mean of the stress level at the time T1 and compare it to the value at the time $\mathrm{T} 2$, we can conclude that the average value of the stress at time T2 is lower than that of time T1, but we could not be sure that the difference between the average level of stress in these two periods directly indicates a reduction in stress or that the employees who did not answer had a higher value than those who responded, that can make more sense if there are a large amount of data that cannot be verified manually. For this reason, a model of statistics will be applied that is "paired_sample T-test" to really compare the two levels of stress, when there are 'pairs' of data in the periods T1 and T2. This operation checks the significance of the paired changes occurred between the two levels stress in another way: it identifies the change on one particular metric for a group of individuals over time as shown in Figure 7.

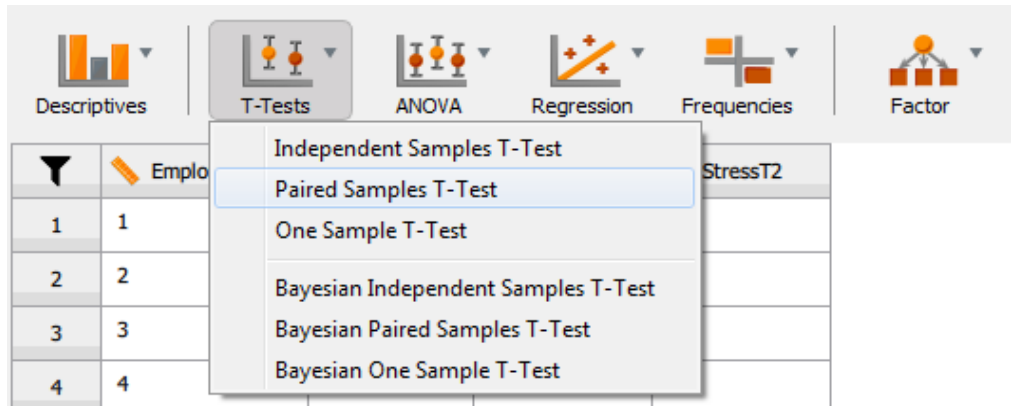

Figure 7. Applying the Paired Samples T-test model

\subsubsection{Results}

The statistical analysis that we use for this case study is: paired sample t-test. Here are the analytics results that we will discuss to show the impact of the stress in the workplace. The JASP output interface shows a lot of information as shown in Figures 8 and 9, but we focused only on the important results that will help us to show if there has been a significant change in the metrics or measurement over time, thus means that the intervention really has an impact. 
Paired Samples T-Test

\begin{tabular}{|c|c|c|c|c|c|c|c|}
\hline & & $t$ & $d f$ & $p$ & Mean Difference & SE Difference & Cohen's d \\
\hline StressT1 & StressT2 & 22.36 & 401 & $<.001$ & 1.378 & 0.062 & 1.115 \\
\hline
\end{tabular}

Descriptives

Descriptives

\begin{tabular}{lllll}
\hline & N & Mean & SD & SE \\
\hline StressT1 & 402 & 3.595 & 1.106 & 0.055 \\
StressT2 & 402 & 2.216 & 0.932 & 0.046 \\
\hline
\end{tabular}

Figure 8. Results of measuring the stress level after and before intervention

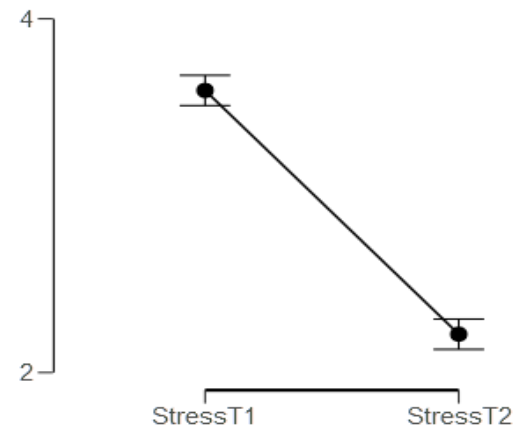

Figure 9. Graphical display of the measures

\subsubsection{Discussion}

The results in Figure 8, give us very important information, The descriptive box shows the mean levels of stress at T1 $(3,95)$ and T2 $(2,216)$. So, it is clear that a group is greater and has higher mean level stress, than another period, in addition of standard deviation and the standard error for each level, also the $\mathrm{N}$ of the paired data, as well as information about how the stress levels tend to vary. We can see clearly that $\mathrm{N}$ here is 402 rather than 406 , this means that only 4 employees didn't complete their information concerned the stress at time 1 and time 2 .

The second box of "paired samples statistics" shows us if this change is significant or not, The major key here is T value which is 22,6; this is the output result of the $401 \mathrm{df}$ (degrees of freedom), and the probability value $(\mathrm{P})$ is less than 0,001 which does imply that there is a significant difference between the two levels. We can also look at the effect size which is 1,115 , also the graphical display of the measures means and their associated 95\% credible intervals as shown in Figure 9, shows a large significant difference between stressT1 and stressT2. We conclude that since the mean difference is so great that it is due to the experimenter's manipulation and it does not simply due to other reasons.

In summary, the stress level is higher at time 1 than at time 2, the mean stress level decreased from 3,9 to 2,2 and this change is significant, which acknowledged that the larger the difference between the means the more we can assume that it is due to what we have manipulated (the new program of work), in another way there is evidence that the new program of work (less number of hours work + motivations) had a positive impact on stress levels. So organizations should think more seriously in comfortable conditions through which to reduce the stress so employees, which increases the production and profitability.

To conclude, it is important to identify when an intervention has negative or positive outcome. Tracking the impact of an intervention help the company to identify whether the investment has paid off or whether is it having negative consequence, so, that help to make a decision. But the major obstacle is, this way does not provide a complete solution it focusses only on one dimension which is technological, in addition, it suffering from the problems mentioned above (Not possible to do any changes, often need additional software for data cleaning and munging, need some skills to use saving or scripting analysis Pipelines not simple...), in the following section, we present a proposed solution that will be a better method to draw better results of analysis. 


\subsection{Solution: Proposed Analytics Framework}

As it clear above, it is necessary to affirm that because of the missing data, errors, lack of seriousness of some employees in completing the questionnaire it would have to be very careful to draw any conclusions about results, the existing analytics solution analyzes revolve only around technology and its relation to data, it does not take into consideration the other dimensions that can be influencing the results and will automatically be influencing the decision-making, and for that we have to propose a multidimensional framework that is going to be a complete solution that brings together the different dimensions so their interactions between them, these dimensions are only the regulatory dimensions of the company [22], so it an objective framework for adding value to HR in the environment of enterprise, this framework presents a complete model that combine several dimensions interact with each other and Proposed analytics framework as shown in Figure 10:

a. Actors: this dimension includes enterprise staff, software developers, customers, managers...

b. Enterprise information: the organization content includes attitude data of employees, stuff details and performance, promotions details, customer's information.

c. Organizational objectives: the strategic goals that the organization is trying to achieve.

d. HR activities: activities and processes which are measured using the so-called efficiency metrics.

e. HR outcomes: outcomes that are traditionally seen as an essential HR KPIs.

f. Interaction models: Interface between the system aspects and users.

g. Computing infrastructure: the hardware and software required.

h. Communication: Business 'workflow as a collaboration that requires significant two-way communication.

i. Data sources: the source systems such as: databases, data-warehouses, supply chain systems, surveys and other operational systems.

j. Internal processes: a large amount of operations include organizational policies, procedures and culture, purchase of hardware and software, data backups ...

k. External processes: it is the forces presented as external rules, regulations pressures that place constraints or help on the deployment.

1. Regular basis measuring and monitoring of the effects of information technology.

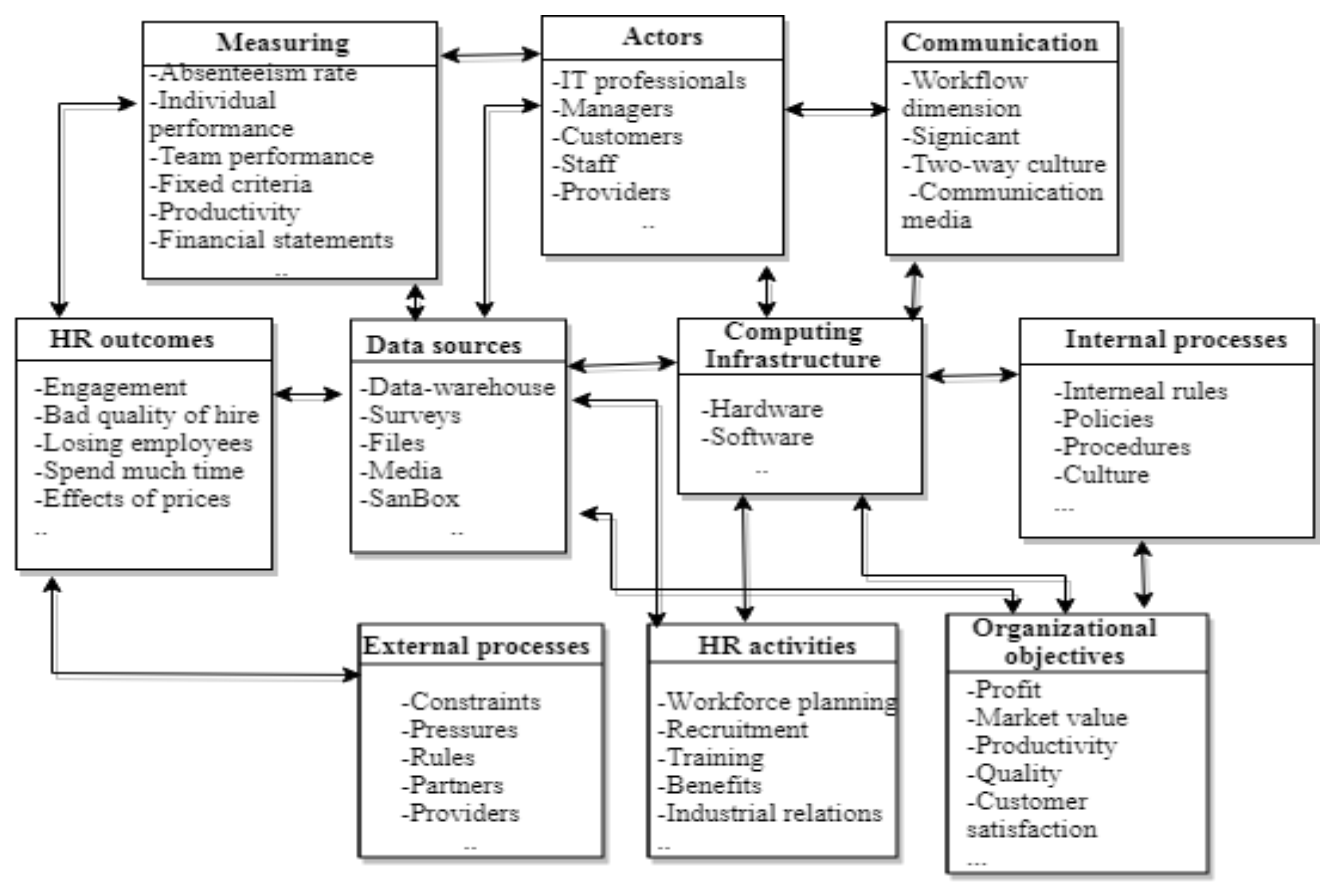

Figure 10. Proposed analytics framework

\subsubsection{Benefits}

The above framework presents a complete model inspired from the regulatory dimensions that make up the enterprise and make of it a global company [23]. It simply offers the possibility of its hierarchical 
decomposition, in other words, the possibility of decomposing either a system, a process, or a complex device into detached components, which offers the possibility of its manipulation, studying and then to integrate the results into, trying to understand the operation and functioning of a complete system. This model can offer the possibility of improving and augment management reports and dashboards with a thorough and deep insight of past, current and even future performance.

\subsubsection{Barriers}

The challenge is using of analytics within enterprises and to identify clearly the key steps to set up an analytic framework as a road towards an organization's analytics maturity, but the problem is not only to find a complete framework [24], the analytics deployment confronted other limits as [25]:

a. Strategic analytics for enterprise costs much.

b. Limited use due to the quality of information and Data flexibility.

c. Distrust of the information and gaps to extract correct data.

d. Lack of experienced people that can understand and deploy the analytical systems.

e. Models are complex to deploy and take much time.

f. Turn information and insights into decision requires an immense experience.

\section{CONCLUSION}

In this paper, we described this HR analytics approach for the company as a set of analysis that comes to drive business planning and deploy the future business planning, as well as some, current analytics technique and solutions with a short comparison. So, we finalize with a case study in which we analyzed and discussed the tracking of interventions. This case study is generally an example of the HR analytics power, where the company has set up conditions where important predicted outcomes of an intervention are created or metrics are made available to control and monitor whether an intervention has the wanted impact, in the light of this case study we have shed light on the shortcomings of these existing solutions and we propose a complete framework that will bring solutions to the current models problems.

HR analytics generates potential benefits for the company. It is the major key behind the reaching of business goals. For this, our future contribution will be about concretizing this notion of HR analytics by a specific and original approach about scenario modeling, even predicting employee performance.

\section{REFERENCES}

[1] Mustakim M, Novia KS, Jasril J, Ismu K, Nurul GIR. "Eigenvalue of Analytic Hierarchy Process as The Determinant for Class Target on Classification Algorithm”. Indonesian Journal of Electrical Engineering and Computer Science(IJEECS). 2018; 12(3): 1257-1264.

[2] Chen H, Chiang RHL, Storey VC. "Business Intelligence and Analytics: from Big Data to Big Impact. MIS quarterly. 2012; 36(4): 1165-1188.

[3] Levenson A. "Harnessing the Power of HR Analytics". Strategic HR Review. 2005; 4(3): 28-31.

[4] Halim MZA, Rosli MM. A Modular and Extensible Framework for Human Resource System. Indonesian Journal of Electrical Engineering and Computer Science(IJEECS).2018; 12(2): 641-647.

[5] Lawler III EE, Levenson A, Boudreau JW. HR Metrics and Analytics-Uses and Impacts. Human Resource Planning Journal. 2004; 27(4) : 27-35.

[6] Jac FENZ. The New HR Analytics: Predicting the Economic Value of Your Company's Human Capital Investments. New York: Amacom, 2010.

[7] Edwards MR, Edwards K. "Predictive HR Analytics: Mastering the HR Metric". Kogan Page Publishers, 2016.

[8] Sambo F, Bankole FO. "A Normative Process Model for ICT Business Continuity Plan for Disaster Event in Small, Medium and Large Enterprises". International Journal of Electrical and Computer Engineering (IJECE). 2016; 6(5): 2425-2431.

[9] Delen D, Demirkan H. Data, Information and Analytics As Services”. Elsevier Science Publishers. 2013; 55(1): 359-363.

[10] Eckerson WW. Predictive analytics. "Extending the Value of Your Data Warehousing Investment". TDWI Best Practices Report. 2007; 1(1): 1-36.

[11] Ransbotham S, Kiron D, Prentice PK. "Minding the Analytics Gap". MIT Sloan Management Review. 2015; 56(4): $1-16$.

[12] Thomas JJ, Cook KA. "A Visual Analytics Agenda". IEEE computer graphics and applications. 2006; 26(1): 1013.

[13] Fang LY, Azmi NFM, Yahya Y, Sarkan H, Sjarif NNA, Chuprat S. "Mobile Business Intelligence Acceptance Model for Organisational Decision Making". Bulletin of Electrical Engineering and Informatics(BEEI). 2018; 7(4): 650-656. 
[14] Chen H, Mao H. "Application of Computer Software in Analyzing Sound Acquisition in Modern Standard Chinese". Indonesian Journal of Electrical Engineering and Computer Science(IJEECS). 2013; 11(8): 4824-4831.

[15] Feinberg M, Siekpe J. "An Empirical Comparison Of Student User-Satisfactionbetween Spss And Minitab". College Student Journal. 2003; 37(4): 509-514.

[16] Ward BW. "What's Better-R, SAS, SPSS, or Stata? Thoughts for Instructors of Statistics and Research Methods Courses". Journal of Applied Social Science. 2013; 7(1): 115-120.

[17] Mike G, Rowan C. "The Forrester Wave ${ }^{\mathrm{TM}}$ : Big Data Predictive Analytics Solutions", Q1 2013. Cambridge: Forrester Research. 2013.

[18] Marsman M, Wagenmakers EJ. "Bayesian Benefits with JASP. European Journal of Developmental Psychology. 2017; 14(5): 545-555.

[19] Zhao S, Meng X, Foong PS, Perrault S. “A Dummy's Guide to your Next EXPeriment: Experimental Design and Analysis Made Easy". Proceedings of the 2016 CHI Conference Extended Abstracts on Human Factors in Computing Systems. ACM, California. 2016: 1016-1019.

[20] Mee RW, Chua TC. "Regression Toward The Mean And The Paired Sample T Test". The American Statistician. 1991; 45(1): 39-42.

[21] Chandola T. Stress at work. "The British Academy". London. 2010: 5-24.

[22] Doumeingts G, Vallespir B, Chen D, "Decision Modelling GRAI Grid". in: Bernus P, Mertins K, Schmidt G. (Eds.). Handbook on Architecture for Information Systems. Berling: Springer-Verlag. 1998: 38-57.

[23] Tan J. "Regulatory Environment and Strategic Orientations in A Transitional Economy: A Study of Chinese Private Enterprise". Entrepreneurship theory and Practice. 1996; 21(1): 31-46.

[24] Williams I, Bryan S. "Understanding the Limited Impact of Economic Evaluation in Health Care Resource Allocation: A Conceptual Framework". Health policy. 2007; 80(1): 135-143.

[25] Ferguson R, Macfadyen LP, Clow D, Tynan B, Alexander S, Dawson S, (2015). "Setting Learning Analytics in Context: Overcoming the Barriers to Large-Scale Adoption". Journal of Learning Analytics. 2015; 1(3): 120-144. 